Working

Paper

Department

of Economics

$\mathrm{Ca}^{\prime}$ Foscari University of

Venice

Carlo Carraro

Enrica De Cian

Massimo Tavoni

Human capital formation and global warming mitigation: evidence from an integrated assessment modelt 


\title{
Human capital formation and global warming mitigation: evidence from an integrated assessment model
}

\author{
Carlo Carraro, University of Venice, Fondazione Enrico Mattei, CEPR, CESifo and CMCC, \\ Enrica De Cian, University of Venice, and Fondazione Enrico Mattei \\ and \\ Massimo Tavoni, Princeton University and Fondazione Enrico Mattei
}

First Draft: June 2008; This Draft: November 2009

\begin{abstract}
Whereas the linkage between technology and climate policy has been extensively analysed, the interaction between climate policies and human capital formation has received considerably less attention. Human capital is a determinant of economic growth and, at the same time, it affects the efficiency of responses to climate change. Based on recent empirical evidence, this paper includes human capital and knowledge in a state-of-the art integrated assessment model. Introducing human capital makes it possible to assess the interplay between innovation, human capital, climate change, and education policies.

Results indicate that climate policy stimulates a dedicated form of energy-knowledge without reducing generic R\&D investments. Since advancements in labour productivity have a negative impact on the environment because labour is assumed to be complement to energy, climate policy reduces education investments, on which human capital is built. However, inspection of a policy mix combining climate and education targets shows that education and climate goals can be coupled incurring in small additional economic penalties. We thus provide evidence that apparently opposing policy goals can and should be pursued together. We also provide a preliminary investigation of knowledge stimulating education.
\end{abstract}

Keywords

Climate Policy, Innovation, Human capital

JEL Codes

O33, O41, Q43

Address for correspondence:

Enrica De Cian

Fondazione Eni Enrico Mattei,

Campo S. Maria Formosa, Castello 5252, 30122 Venice, Italy

e-mail: enrica.decian@feem.it

This Working Paper is published under the auspices of the Department of Economics of the Ca' Foscari University of Venice. Opinions expressed herein are those of the authors and not those of the Department. The Working Paper series is designed to divulge preliminary or incomplete work, circulated to favour discussion and comments. Citation of this paper should consider its provisional character.

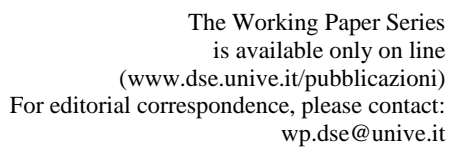

The Working Paper Series (www dse unive.

wp.dse@unive.it
Department of Economic

Ca' Foscari University of Venice

Cannaregio 873, Fondamenta San Giobbe

30121 Venice Italy

Fax: ++39 0412349210 


\section{Introduction}

Innovation, technology development and deployment are topics that increasingly interest policy makers dealing with climate change. Researchers have developed a range of tools to conceptualise these issues and to provide indications on cost-effective solutions to the climate-technology challenge. Our understanding of the role of technological change has improved over the last decades. However, what is the most appropriate way of modelling technical change is still a debated issue.

Most climate-economy models have focused on the evolution of technical change in the energy sector. The majority of Integrated Assessment Models (IAMs) now include modules that describe energy-related technical change as an endogenous process driven by either innovation or experience. In most cases, other forms of technical change that are either capital- or labouraugmenting have been omitted or approximated with exogenous trends. As a consequence, mitigation policies can only influence energy-saving technology and what happens to the overall rate of technical change is not specified.

Recent empirical evidence suggests that technical change is both energy-saving and energy-using ${ }^{1}$ and that the productivity of production factors increases at different rates (van der Werf 2008, Carraro and De Cian 2009). Rising energy prices and more stringent environmental policies stimulate innovation in the energy field (Jaffe and Palmer 1997, Popp 2002). Still other forms of innovation (e.g. labour- or capital-saving) will continue to occur. In the literature there is a gap between empirical results and the frameworks adopted by modellers to characterise the dynamics of

\footnotetext{
${ }^{1}$ Technical change is input-saving if the input cost share decreases at constant factor prices. It is input-using if the input cost share increases at constant factor prices. It is input-augmenting if it increases input productivity.
} 
technical change. To date, only few models parameterise these relationship based on empirical data $^{2}$.

Whether technical change is good or bad for the environment depends on the direction it takes and the substitution possibilities among inputs. If pollution-saving technical change dominates pollution-using technical change, such as total factor productivity, sustainable growth is attainable (Bovenberg and Smulders 1995, Brock and Taylor 2005, Lopez 1994). If technical change increases the productivity of inputs that are a gross complement to emissions, it may eventually increase pollution (Lopez 1994). For example, if energy is gross complement to labour and capital, capitalor labour-augmenting technical change would increase emissions.

To date, only few IAMs feature pollution-using and endogenous technical change (Goulder and Schneider 1999, Gerlagh 2008, Carraro et al. 2009). These models assume that technological advancements in both energy- and non-energy sectors are driven by a stock of knowledge accumulated with $R \& D$ investments. Climate policy can induce a reallocation of $R \& D$ investments between the energy and non-energy sector.

Goulder and Schneider (1999) introduced sector-specific, neutral innovation in a dynamic general equilibrium model. Climate policy stimulates innovation in alternative energy industries, but it discourages $\mathrm{R} \& \mathrm{D}$ in non-energy sectors. This decline causes a contraction of total output, reducing the economy-wide rate of technical progress. Gerlagh (2008) developed a model with three forms of R\&D-driven innovation. A first stock of knowledge increases the productivity of carbon-energy production. A second stock is carbon-energy saving and a third stock is neutral. He found that climate policy shifts resources from energy production to energy-saving technical change. If a sufficient amount of investments go to energy-saving technical change, then there might be a research dividend and overall research levels may increase. On the contrary, Carraro et al. (2009) found that a climate policy re-direct technical change towards the energy sector, reducing the overall rate of technical change. This effect is not due to crowding-out between energy and nonenergy R\&D investments, but it is caused by contraction of the overall economic activity.

Following mainstream growth theory, climate-economy models describe technical change as a process driven by the accumulation of knowledge and /or experience. Another important source of technical progress is human capital (Lucas 1998, Blankenau and Simpson 2004). The theoretical

\footnotetext{
${ }^{2}$ The gap between the empirical and modelling literature has been extensively analysed in the Special Issue on Technology and Environment, Energy Economics 30, 2008.
} 
literature has investigated the interaction between human capital, innovation and the environment, but not specifically with climate policy (Gradus and Smulders 1993, Hettich 1998, Pautrel 2008, Grimaud and Tournemaine 2007, Ikazaki 2006).

This literature highlights how the relationship between environmental, human capital formation and economic growth hinges on the way human capital and education come into the model. Whether education is included in the utility function or treated as a production input affects the results. What is the source of pollution, either output or inputs such as physical capital, also plays a role. When pollution is linked to final output, an environmental tax reduces the returns on both capital and labour, reducing the incentive for human capital formation (Hettich 1998, Gradus and Smulder 1993). Instead, when pollution depends on physical capital, an environmental tax increases wages relative to capital returns, stimulating education investments. Grimaud and Tournemaine (2007) developed a model with pollution-saving R\&D and with education. Education enters in the utility function together with consumption of the polluting good. In that framework, environmental policy can promote economic growth because a tax on pollution shifts consumption toward the less costly good, namely education.

Blankenau and Simpson (2004) developed a growth model to study the relationship between public education expenditure and growth. Education spending can increase growth, but general equilibrium effects may crowd out other sources of growth, such as investments in physical capital and private human capital. The magnitude of crowding-out depends on the size of the public sector and how education expenditure is financed. When financed with consumption taxes, education has a positive effect on growth.

Despite these theoretical contributions, the applied climate-economy literature has overlooked the role of human capital as source of economic growth. The role of education in climate policy has already been acknowledged in the Third Assessment Report of the IPCC, which has identified education and the stock of human capital as one of the determinants of adaptive capacity. According to Yohe (2001), human capital not only affects the ability to respond to climate variability and change, but it is also a determinant of mitigative capacity. In the real world, climate policy concurs with other policy goals. For example, the Millennium Development Goals define eight objectives that should be simultaneously achieved by 2015. Two of them are universal primary education and sustainable development. 
Regarding human capital and climate policies, there are several questions that could interest policy makers. What is the effect of human capital on emissions? What is the impact of climate policy on human capital formation? Is there substitution between investments for innovation and human capital? Can education and climate objectives be pursued together? At what costs?

This paper addresses some of these issues using an Integrated Assessment Model. This approach is meant to advance the current status of climate change economics research and to clarify some of the connections between climate change and economic development. To our knowledge, this is a first modelling assessment of the interplay between two important determinants of economic growth, innovation and human capital, in the context of climate policy.

This paper also attempts at closing the gap between empirical and applied literature. The framework that describes the relationship between innovation, human capital and productivity growth is based on the empirical results described in Carraro and De Cian (2009). The model features not only endogenous energy-saving technical change, but it also includes human capital as a source of labour productivity and generic innovation as a source of both energy and capital productivity.

Our results indicate that climate policy stimulates a dedicated form of energy knowledge without reducing total $R \& D$ investments. Climate policy, which favours cost-effective mitigation options, penalises the formation of human capital. What drives this result is the pollution-using effect of human capital and the gross complementarity between labour and energy input. With a slightly different set-up, Carraro et al. (2009) also conclude that the degree of substitution between energy and non-energy inputs determine the final effect of technical change. We find that innovation and human capital are complements rather than substitutes because education policy stimulates both energy and generic innovation. The human capital crowding out induced by climate policy is lessened when education contributes to knowledge formation.

The rest of the paper is organised as follows. Section 2 describes the WITCH model and the new structure of production. Section 3 briefly illustrates the calibration process and the baseline scenario. It also examines the model sensitivity to human capital. Policy scenarios are described in Section 4. Section 5 provides a preliminary assessment of the interactions between innovation and human. Section 6 concludes. 


\section{Factor-augmenting technical change in the WITCH model}

\subsection{Short model description}

The WITCH model (Bosetti et al. 2006, Bosetti et al. 2007) is a hard-linked, energy-economyclimate model designed to deal with the main features of climate change. It is a global model and the world economy is disaggregated into twelve macro regions. The model considers the noncooperative nature of international relationships. Regions interact with each other because of the presence of economic and environmental global externalities. It is a forward-looking model and each regional social planner maximises her own intertemporal welfare taking as given the behaviour of other regions.

The model proposes a bottom-up characterisation of the energy sector. Seven different energygenerating technologies are modelled: coal, oil, gas, wind \& solar, nuclear, electricity, and biofuels. The model includes two breakthrough technologies whose penetration rate is driven by innovation. It distinguishes dedicated $R \& D$ investments for enhancing energy efficiency from investments aimed at facilitating the competitiveness of innovative low carbon technologies in both the electric and non-electric sectors (backstops). R\&D processes are subject to stand on shoulders as well on neighbouring effects. Specifically, international spillovers of knowledge are accounted to mimic the flow of ideas and knowledge across countries. Finally, experience processes through Learning-byDoing are accounted for in the development of niche technologies such as renewable energy (Wind\&Solar) and the backstops.

Through the optimisation process regions choose the optimal dynamic path of different investments, namely in physical capital, in R\&D and energy technologies. Recently, the WITCH model has been updated with more recent data. It has revised estimates for future projection of the main exogenous drivers. Socio-economic, energy and environmental variables have been re-calibrated to the year 2005 (Bosetti et al. 2009). The model described in this study has been developed starting from the re-calibrated version of WITCH.

Carraro et al. (2009) has proposed an alternative version which adds non-energy innovation. A stock of knowledge improves the productivity of the capita-labour nest. This modification makes it possible to study the impact of climate policies on the direction of technical change. However, the source of technical progress remains the accumulation of knowledge capital. 
In a similar way, we add a generic form of knowledge that affects not only energy, but also capital productivity. We go a step further and we also include another source of technical progress, namely human capital. Next section describes in detail the structure of production and of endogenous technical change.

\subsection{Production structure and input endogenous technical change}

Regional production is described by a Constant Elasticity of Substitution (CES) technology. This technology combines capital $(K)$, labour $(L)$, and energy $(E)$ to produce a final good that can be used for consumption or investment. Factors of production are expressed in efficiency units. The multiplicative coefficients $\left(A_{i}\right)$ represent the productivity of production factors, which improves over time endogenously. This formulation is also referred to as endogenous factor-augmenting technical change. Overall productivity is described by the parameter $(H)$, which instead evolves exogenously. It can be seen as a scale factor that represents the efficiency with which total output is produced. This component has a neutral effect because it does not modify the ratio of marginal productivities (Hicks neutral). We adopt a non-nested specification, as estimated in Carraro and De Cian (2009). The empirical evidence on different nesting structure and on the proper value of the elasticity of substitution is mixed. A robust finding is that capital, labour, and energy are gross complements and thus the elasticity of substitution between these factors is less than one ${ }^{3}$. Equation 1 summarises the new features of the production structure:

$Y(n, t)=H(n, t) \frac{\left(A K(n, t) K(n, t)^{\rho Y}+A L(n, t) L(n, t)^{\rho Y}+A E N(n, t) E N(n, t)^{\rho Y}\right)^{\frac{1}{\rho Y}}}{\Omega(n ; t)}$

where $\Omega$ is the climate change damage function which expresses a reduced-form relationship between output and temperature increase above pre-industrial levels.

The dynamic path that characterises the evolution of factor productivities has been modelled following Carraro and De Cian (2009). The empirical evidence on the direction and the sources of factor-augmenting technical change is still very scarce. Most studies have analysed the determinants of neutral technical change, conventionally measured as total factor productivity. Only recently the possible sources of factor-augmenting technical change have also been studied. Carraro and De

\footnotetext{
${ }^{3}$ Reviews of the estimates of substitution elasticity are provided in Carraro et al. (2009), Markandya et al. (2007) and Acemoglu (2003).
} 
Cian (2009) have identified potential technology drivers that lead to factor improvements. They assume that factor-augmenting technical change consists of two components. An exogenous term that captures the autonomous time evolution of technical change and an endogenous term $\left(\chi_{i}\right)$ that links factor productivity to other economic variables. Empirical results suggest that capital and energy productivities improve with the stock of total $R \& D$, whereas the stock of education feeds labour productivity. Estimated elasticises with respect the stock of R\&D and education are reported in Table 1.

Table 1. Factor elasticities to endogenous technology drivers

\begin{tabular}{c|c}
\hline$\chi_{L}\left(E D U_{S}\right)$ & 0.17 \\
$\chi_{E}\left(R \& D_{S}\right)$ & 0.60 \\
$\chi_{K}\left(R \& D_{S}\right)$ & 0.26
\end{tabular}

Results in Table 1 are used to calibrate the endogenous path of factor productivities in the WITCH model. Their dynamics are described by the following equations:

$$
\begin{aligned}
& A K(n, t)=A K 0(n, t)\left(\frac{R \& D s(n, t)}{R \& D s(n, 0)}\right)^{\chi_{K}} \\
& A E(n, t)=A E 0(n, t)\left(\frac{R \& D s(n, t)}{R \& D s(n, 0)}\right)^{\chi_{E}} \\
& A L(n, t)=A L 0(n, t)\left(\frac{E D U s(n, t)}{E D U s(n, 0)}\right)^{\chi_{L}}
\end{aligned}
$$

Capital and energy productivities depend on an indicator of knowledge (the stock of total R\&D) normalised to the base year, $R \& D_{S}(n, 0)$. Labour productivity is instead related to an indicator of human capital (the stock of total education expenditure). The parameters AiO represent the autonomous component of factor productivities, which evolve exogenously.

The production of both human capital and knowledge is characterised by intertemporal spillovers, as the stock available in the economy at each point in time contributes to the creation of the future stock. Knowledge spillovers from the past are essential for the production of new knowledge. Following state-of-the-art literature (Romer 1990, Jones 1995, Popp 2002, Glomm and Ravikumar 1997, Blankenau and Simpson 2004) we assume that human capital $\left(Z_{E D U}\right)$ is produced using a Cobb Douglas combination between the existing stock of human capital $\left(E D U_{S}\right)$ and current 
expenditure in education $\left(I_{E D U}\right)$. In a similar way, the available knowledge stock $\left(R \& D_{s}\right)$ and current R\&D investments $\left(I_{R \& D}\right)$ are combined to produce knowledge capital $\left(Z_{R \& D}\right)$. The sum of the exponents is less than one to account for diminishing returns on education and R\&D:

$Z_{E D U}(n, t)=\alpha_{E D U} I_{E D U}^{\beta_{E D U}} E D U_{S}^{\varphi_{E D U}}$

$Z_{R \& D}(n, t)=\alpha_{R \& D} I_{R \& D}^{\beta_{R \& D}} R \& D_{S}^{\varphi_{T R \& D}}$

where

$\beta_{E D U}+\varphi_{E D U}<1$

$\beta_{R \& D}+\varphi_{R \& D}<1$

The stock of both knowledge and human capital depreciate over time. Following Jorgenson and Fraumeni (1992), the depreciation rate of human capital $\left(\delta_{E D U}\right)$ is lower than the depreciation rate of knowledge $\left(\delta_{R \& D}\right)$ (2\% and $5 \%$ per year respectively). The final laws of accumulation read as follows:

$E D U_{S}(n, t+1)=E D U_{S}(n, t)\left(1-\delta_{E D U}\right)+Z_{E D U}(n, t)$

$R \& D_{S}(n, t+1)=R \& D_{S}(n, t)\left(1-\delta_{R \& D}\right)+Z_{R \& D}(n, t)$

Investments in R\&D that build up the stock in equation (4) represent the total innovative activity of the economy, without sectoral distinctions. Therefore, we also refer to it as generic innovation. As mentioned before, resources can also be allocated to dedicated investments in energy R\&D. Investments in energy $\mathrm{R} \& \mathrm{D}\left(I_{E R \& D}\right)$ build up the formation of a stock of dedicated knowledge $\left(Z_{E R \& D}\right)$ :

$Z_{E R \& D}(n, t)=\alpha_{E R \& D} I_{E R \& D}^{\beta_{E R \& D}} E R \& D_{S}^{\varphi_{E R \& D}}$

where

$\beta_{E R \& D}+\varphi_{E R \& D}<1$

with the standard accumulation equation:

$E R \& D_{S}(n, t+1)=E R \& D_{S}(n, t)\left(1-\delta_{E R \& D}\right)+Z_{E R \& D}(n, t)$ 
Investments in energy R\&D add to the effect of generic $R \& D$ and they both contribute the final improvement of energy productivity ${ }^{4}$ :

$$
A E(n, t)=A E 0(n, t)\left(\frac{R \& D s(n, t)+E R \& D s(n, t)}{R \& D s(n, 0)+E R \& D s(n, 0}\right)^{\chi_{E}}
$$

Investments in generic $R \& D$, energy $R \& D$ and expenditure on education reduce resources available for consumption and other investment opportunities, according to the standard budget constraint:

$$
C(n, t)=Y(n, t)-\sum_{i} I_{i}(n, t)-I_{R \& D}(n, t)-I_{E R \& D}(n, t)-I_{E D U}(n, t)-I_{C}(n, t)
$$

\section{Calibration and baseline scenario}

\section{1 Baseline scenario}

The present version of the WITCH model has been calibrated on the updated version of the base model (Bosetti et al. 2009) ${ }^{5 \cdot}$ In the present version, the endogenous dynamic of factor productivities is an important driver of economic growth. Factor productivities grow endogenously with human capital and knowledge. The average growth rates of factor productivities are reported in Table 2, together with the average growth rate of neutral technical change.

\begin{tabular}{|c|c|c|c|c|c|c|c|c|c|c|c|c|}
\hline & USA & WEURO & EEURO & KOSAU & CAJAZ & TE & MENA & SSA & SASIA & CHINA & EASIA & LACA \\
\hline $\boldsymbol{H}$ & $0.44 \%$ & $0.75 \%$ & $1.63 \%$ & $1.05 \%$ & $0.76 \%$ & $1.60 \%$ & $1.47 \%$ & $2.34 \%$ & $2.46 \%$ & $2.33 \%$ & $1.41 \%$ & $1.69 \%$ \\
\hline$A E$ & $0.81 \%$ & $0.50 \%$ & $0.66 \%$ & $0.50 \%$ & $0.59 \%$ & $0.45 \%$ & $0.77 \%$ & $1.24 \%$ & $1.21 \%$ & $0.99 \%$ & $1.85 \%$ & $0.70 \%$ \\
\hline$A K$ & $0.55 \%$ & $0.32 \%$ & $0.27 \%$ & $0.23 \%$ & $0.31 \%$ & $0.25 \%$ & $0.42 \%$ & $0.27 \%$ & $0.59 \%$ & $0.62 \%$ & $0.91 \%$ & $0.19 \%$ \\
\hline$A L$ & $0.65 \%$ & $0.50 \%$ & $0.82 \%$ & $0.38 \%$ & $0.31 \%$ & $0.63 \%$ & $0.70 \%$ & $0.34 \%$ & $0.80 \%$ & $0.97 \%$ & $0.87 \%$ & $0.82 \%$ \\
\hline
\end{tabular}

Table 2. Factor-augmenting technical change: average growth rates

In non-OECD countries and Eastern Europe, the productivity of all factors grows faster than OECD countries, driving the convergence process that characterises the baseline. It should be pointed out

\footnotetext{
${ }^{4}$ We implicitly assumed that energy R\&D and generic R\&D have the same effect on energy productivity. We did not have any empirical information to distinguish between the two stocks of knowledge.

${ }^{5}$ Major modifications are the inclusion of non-CO2 GHGs, the representation of two breakthrough technologies and the updating of the base year to 2005.
} 
that, despite the endogenous characterisation of factor productivities, neutral technical change, which is exogenous, still plays a large role ${ }^{6}$.

Figure 1 highlights the contribution of endogenous technical change to economic growth. It shows Gross World Product (GWP) in the Baseline scenario (BaU), when all factor productivities are endogenous, together with other two scenarios. The red line (Exogenous $A L$ ) is the path of Gross World Product when the endogenous component of labour productivity is switched off, e.g. only capital and energy productivities are endogenous. The green line (Exogenous TC) is the path of Gross World Product when all productivities are assumed to be exogenous. Endogenous technical change contributes to $30 \%$ of economic growth in 2100 . The graph shows that the main endogenous engine of economic growth is human capital, with a contribution of $26 \%$ at the end of the century.

Figure 1. Gross World Product under different technology assumptions

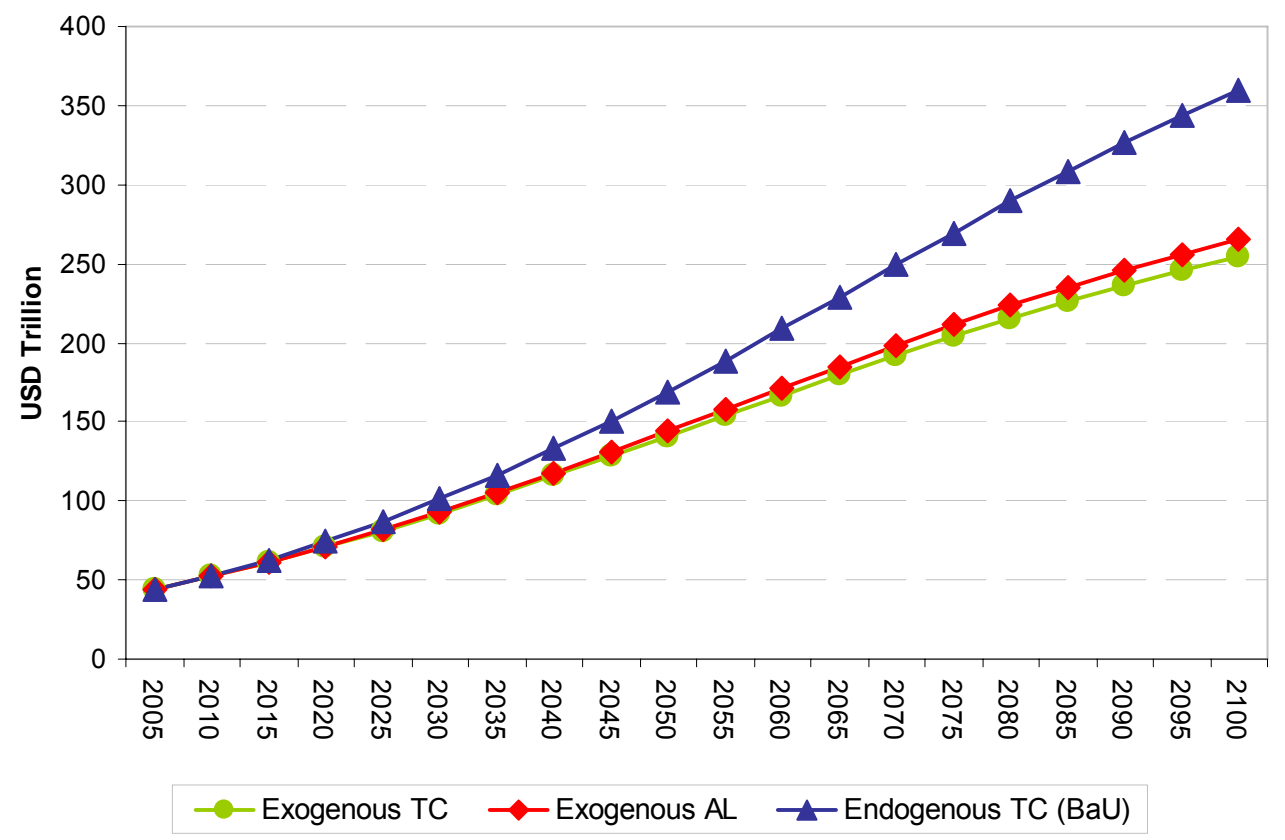

Education and R\&D investments have been calibrated on historical regional shares over GDP. World expenditure on generic R\&D in 2005 is 2.13\% of GWP, global education expenditure

\footnotetext{
${ }^{6}$ As mentioned in the previous section, factor productivities consist of two components, an exogenous trend and an endogenous part. Carraro and De Cian (2009) find that the exogenous component is statistically equal across inputs. Therefore, we calibrated the exogenous component of capital and energy productivity equal to the trend of labour productivity. Labour productivity exogenous trends and neutral technical change have been calibrated to reproduce carbon emissions and regional GDP of the updated WITCH baseline (Bosetti et al. 2009).
} 
4.52\%. As shown in Table 3, OECD countries have the largest share in both education and R\&D expenditure. Whereas non-OECD countries tend to catch up over time in terms of education expenditure, most R\&D expenditure remains concentrated in OECD countries. At the end of the century, they still detain almost $70 \%$ of world R\&D.

Table 3. R\&D investments and Education expenditure. Historical data and calibration results (\% GDP)

\begin{tabular}{|cccc|}
\hline Historical data - 2005 & Energy R\&D & R\&D & EDUCATION \\
(IEA) & (WDI) & (WDI) \\
OECD & $0.033 \%$ & $2.17 \%$ & $4.34 \%$ \\
NON-OECD & $0.033 \%$ & $2.49 \%$ & $4.55 \%$ \\
WITCH - 2005 & n.a. & $0.93 \%$ & $3.62 \%$ \\
WORLD & $0.026 \%$ & $2.13 \%$ & $4.52 \%$ \\
OECD & $0.028 \%$ & $2.44 \%$ & $4.68 \%$ \\
NON-OECD & $0.018 \%$ & $1.03 \%$ & $3.93 \%$ \\
\hline
\end{tabular}

IEA: International Energy Agency

WDI: World Development Indicators

The size of the elasticity of substitution between factors plays a crucial role in shaping the direction of technical change (Acemoglu, 2009). Inputs are gross complements because the elasticity of substitution is less than one ${ }^{7}$. If inputs are gross complements they can be substituted with each other, but with some rigidities. When an input becomes more productive and there is full employment of resources, additional productivity leads to additional output. This scale effect puts an upward pressure on the demand for other inputs and also energy. As a consequence, carbon emissions increase. This argument neglects the distinction between skilled and unskilled labour, which would make the discussion more complicated. A relationship of complementarity between labour and other inputs (capital) is typically found when skilled labour is considered. Instead, empirical studies found that capital tend to be a substitute for unskilled labour.

In the present model, the stock of human capital drives a form of technical progress that is energyusing because labour and energy are gross complements. The net effect of generic innovation is energy-saving because it improves energy productivity more than capital.

\footnotetext{
${ }^{7}$ Carraro and De Cian (2009) estimated the elasticity of substitution between capital, labour and energy and found a value equal to 0.3 . In the model however, a higher value equal of 0.7 is chosen, mainly for two reasons. First, the model time step is of five years. The elasticity of substitution over five years is higher than the elasticity over one year, as discussed in Pessoa et al. (2007).
} 


\section{2 Model sensitivity to human capital dynamics}

Before analysing climate and education policies, this section illustrates the macroeconomic effects of education expenditure. We have considered an exogenous increase in education expenditure to the level of $5 \%$ of regional GDP and we have computed the elasticity of selected variables to education.

The elasticity of final output to education $(\triangle Y \% / \triangle E D U \%)$ is larger than zero, indicating a positive relationship between education expenditure and output growth. This result is intuitive but not obvious. As discussed in Blankenau and Simpson (2003), it depends on how education expenditure is financed. If it is financed with consumption taxes, the effect is positive. This is what occurs in the WITCH model as education expenditure is financed out of the budget constraint. Additional education expenditure comes at the costs of lower consumption in the short-term. However, already after 2025, the growth effect increases also consumption possibilities.

The expansion of economic activity has two additional effects. Emissions increase because economic growth puts an upward pressure on energy demand. At the same time, economic growth increases the amount of resources available for all forms of innovation, indicating a relationship of complementarity between knowledge and human capital. Both generic and dedicated energy R\&D increase. The energy-saving effect of R\&D explains why, despite the increasing elasticity of output, the elasticity of emissions declines after 2030. In the long-run, the presence of diminishing returns mitigates the effect of education on all variables.

Table 4. Elasticities to education investments when these are increased as shown in the last column.

\begin{tabular}{|c|c|c|c|c|c|c|}
\hline & $\Delta Y \% / \Delta E D U \%$ & $\Delta \mathrm{C} \% / \Delta \mathrm{EDU} \%$ & $\Delta$ EMI\%/ $\%$ EDU\% & $\Delta \mathrm{R} \& \mathrm{D} \% / \Delta \mathrm{EDU} \%$ & $\begin{array}{c}\Delta \text { energy- } \\
\text { R\&D\%/DEDU\% }\end{array}$ & $\Delta \mathrm{EDU} \%$ \\
\hline 2015 & 0.02 & -0.04 & 0.01 & -0.02 & -0.03 & $7.2 \%$ \\
\hline 2030 & 0.07 & 0.02 & 0.06 & 0.04 & 0.03 & $5.1 \%$ \\
\hline 2050 & 0.08 & 0.02 & 0.04 & 0.06 & 0.03 & $5.4 \%$ \\
\hline 2100 & 0.04 & -0.01 & 0.02 & 0.04 & 0.01 & $22.9 \%$ \\
\hline
\end{tabular}

This simple exercise has shown that investing in human capital formation has important effects not only on economic growth and consumption, but also on innovation and emissions. In light of these results, what can we anticipate on the expected effects of climate policy? On the one hand, human capital is pollution-using and therefore it may make the achievement of a stabilisation target more difficult. On the other hand, the positive effect education has on output and overall economic growth may partially compensate the economic loss due to a climate policy. Which effect prevails is an empirical question that is addressed in the next section. 


\section{Policy exercises}

\subsection{Climate Policy}

This section analyses the interplay between output, consumption, innovation and human capital in the presence of climate policy. We assume that all regions agree to cooperate on the stabilisation of GHG concentrations at 550 CO2-eq by 2100. An international cap-and-trade system allows regions to buy and sell permits on the world market so as to achieve the target in the most cost-effective way, equalising marginal costs of abatement across regions ${ }^{8}$. This exercise makes it possible to investigate how climate policy affects the accumulation of knowledge and human capital and ultimately the direction of technical change.

When facing a climate policy constraint, each region reshapes the optimal mix of investments to meet the constraint at the minimum cost. The carbon price signal reallocates resources towards low carbon technologies (nuclear, CCS and renewable energy), energy-saving R\&D, innovation and deployment of breakthrough technologies.

Results reported in Figure 2 show that climate policy stimulates a dedicated form of energyknowledge without reducing investments in generic R\&D. Climate policy stimulates not only energy $R \& D$, but also the generic one and the two types of knowledge are found to be complementary. In percentage terms, climate policy reallocates relatively more resources to energy $R \& D$ because it is more effective at augmenting energy efficiency. In addition, energy $R \& D$ reduces the costs of breakthrough technologies. Generic R\&D raises the productivity of capital, which is complement to energy; however, it also raises the productivity of energy, and this latter effect dominates the other.

Climate policy induces some crowding-out on education expenditure, by at most $10 \%$ at mid century, though it declines afterwards. Human capital is labour-augmenting. Given the complementarity between energy and labour, any form of technical progress that increases the productivity of capital and labour is energy-using and therefore has negative implications on the environment. As a consequence, an increase in human capital tends to have a pollution-using effect. This implies that a cost-effective response to climate policy reallocates investments from education towards pollution-saving options such as R\&D and low carbon technologies.

\footnotetext{
${ }^{8}$ Permits are allocated on an equal per capita basis. This allocation schemes tend to favour developing countries. However, the goal is not to provide a comprehensive evaluation of different policy architectures, but rather to emphasise the trade-off and/or the synergies between different policy goals at the global level.
} 
This result is driven by how pollution is modelled. As already pointed out by Hettich (1998), when pollution is linked to final output, as it is the case in the WITCH model, a pollution tax reduces the returns of both capital and labour, diminishing the incentive to invest in education. The abstraction from any distinction between skilled and unskilled labour force and the assumption of full employment are additional drivers of this result. In the case of generic $R \& D$, as explained above, the positive effect on energy efficiency more than compensates the lower incentive to raise the productivity of capital.

Figure 2 shows the reallocation of productive resources between education, generic $R \& D$, and energy R\&D induced by climate policy. Energy R\&D increases the most in percentage terms, reaching a peak of $0.12 \%$ of GWP between 2015 and 2020. Energy R\&D as a share of GDP has been declining since 1980 when it reached a level equal to $0.08 \%$ of GWP. The increase in energy R\&D is more pronounced in the short-run because innovation is needed to make breakthrough technologies competitive. However, the additional billions invested are a small amount, on average equal to US\$ 60 Billion. Although the percentage variations of generic R\&D and education are smaller, they move a larger amount of resources. Over the century, generic R\&D investments increase on average by US\$ 145 Billions, whereas education expenditure is reduced by US\$ 600 Billion.

Figure 2. Human capital and knowledge in the stabilisation scenario (550 CO2-eq) 


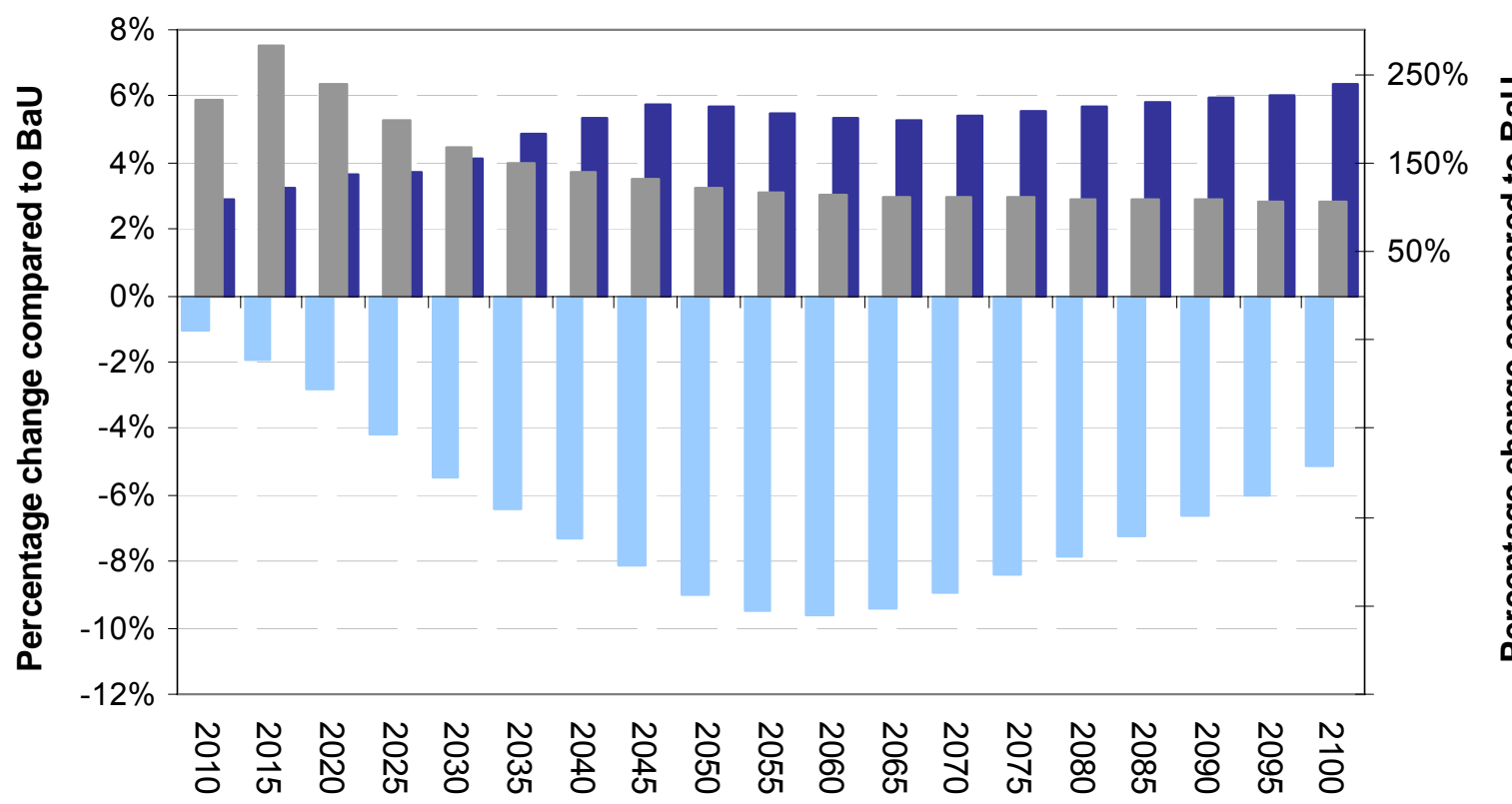

Education expenditure (LHS axes) $\square$ Generic R\&D (LHS axes) — Energy R\&D (RHS axes)

The macroeconomic effects of the stabilisation policy are summarised in Table 5 . The first three columns report the percentage changes of selected variables with respect to the baseline scenario in 2030, 2050 and 2100 respectively. The last column reports the Net Present Value (NPV), using a $3 \%$ discount rate.

Table 5. Global macroeconomic effects of a 550CO2-eq stabilisation policy (Percentage changes w.r.t. BaU)

\begin{tabular}{|l|c|c|c|c|}
\hline & $\mathbf{2 0 3 0}$ & $\mathbf{2 0 5 0}$ & $\mathbf{2 1 0 0}$ & $\begin{array}{c}\text { NPV } \\
\text { (3\% discounting) }\end{array}$ \\
\hline $\begin{array}{l}\text { GROSS WORLD } \\
\text { PRODUCT (GWP) }\end{array}$ & $-1.30 \%$ & $-2.36 \%$ & $0.03 \%$ & $-1.36 \%$ \\
\hline CONSUMPTION & $-0.98 \%$ & $-1.58 \%$ & $0.39 \%$ & $-0.94 \%$ \\
\hline EDUCATION & $-5.47 \%$ & $-9.01 \%$ & $-5.15 \%$ & $-6.20 \%$ \\
\hline GENERIC R\&D & $4.12 \%$ & $5.66 \%$ & $6.37 \%$ & $4.59 \%$ \\
\hline ENERGY R\&D & $167.17 \%$ & $122.70 \%$ & $106.28 \%$ & $149.73 \%$ \\
\hline
\end{tabular}

Macroeconomic costs are within the range of exiting literature (IPCC, 2007), though the climate stabilisation objective considered here is not very ambitious compared to the one of 2 degree Celsius. The RECIPE model intercomparison has analysed the economics of a comparable climate policy and it has found that stabilisation costs range between $1.4 \%$ and $0.1 \%$ of global discounted consumption (Luderer et al. 2009). Low costs are also due to the assumption of immediate 
participation and full flexibility among greenhouse gases abatement options. Departure from any of these assumptions increases costs substantially. For example, Bosetti et al. (2009) found that limited availability of mitigation technologies would impose an additional penalty of roughly $70 \%$ whereas a 20-year delay in global action would increase costs by $160 \%$.

Although this formulation of endogenous technical change has only a minor influence on climate policy costs, the effects on knowledge and human capital formation points at important interactions between different policies. Stabilisation alone induces some crowding-out on education expenditure, but governments may have policies explicitly directed at education. What happens when education and climate goals concurs is discussed in the next section.

\subsection{Coupling climate and education policies}

This section analyses the macroeconomic effects of climate policy in the presence of additional constraints on education expenditure. We assume that governments cannot freely reallocate resources away from education because they have policy targets on education as well. This is actually the case in the 189 countries that have committed to achieve the eight Millennium Development Goals by 2015. Universal primary education and sustainable development are two of the eight Goals. In addition, the Fourth Assessment Report (IPCC, 2007) has stressed the role of capacity building and socio-economic development for effective climate policy. Enhancing each of the determinants of mitigative capacity is a policy objective itself (Yohe, 2001) and education is one of these determinants.

Primary education is almost universal in all developed countries and many developing countries are on the right track to achieve the Millennium Development Goals (on-track countries). Achieving universal primary education is particularly challenging for poor countries such as South Asia (SASIA) and Sub-Saharan Africa (SSA). As a consequence, most countries do not need to invest additional resources on education, but to maintain current levels of expenditure. South Asia and Sub-Saharan Africa instead need to increase investments significantly.

Against this background, we design the following education policy. SSA and SASIA will increase education investments so that the fraction of population currently off-track will be on-track from 
2015 onwards $^{9}$. Other regions will maintain the baseline path of education expenditure, as current spending is already consistent with the achievement of the goal. In order to compute the additional spending on education in SSA and SASIA we combined the percentage of population off-track ${ }^{10}$ from Glewwe et al. (2006) with population projections form the WITCH model. We also used the estimates of average spending per student provided by Glewwe et al. (2006), which amounts to US\$ 46 Billion in SASIA and US\$ 68 Billion in SSA.

Between 2010 and 2015, Sub-Saharan Africa and South Asia increase education expenditure by US\$ 100 Billion a year, which is comparable to current spending on Official Development Assistance $^{11}$. The effect on global education investments is very tiny, as SSA-SASIA education expenditure represents a very small fraction of world education investments.

The macroeconomic effects of combining education and climate policy are shown in Table 6 . Adding the education policy stimulates further innovation, of both types, confirming the complementarity between human capital and innovation. Human capital has a growth effect that ultimately increases the amount of resources available for productive investments, including innovation. The increase in education expenditure puts an upward pressure on emissions as well. However, the impact on the carbon market and the energy mix is very moderate. The price of carbon is only slightly higher, on average 1\%. Investments in carbon-free energy technologies and in energy R\&D slightly increase.

Table 6. Global macroeconomic effects of climate and education policy

(Percentage changes w.r.t. climate policy case)

\begin{tabular}{|l|c|c|c|c|}
\hline & $\mathbf{2 0 3 0}$ & $\mathbf{2 0 5 0}$ & $\mathbf{2 1 0 0}$ & $\begin{array}{c}\text { NPV } \\
\text { (3\% discounting) }\end{array}$ \\
\hline GROSS WORLD PRODUCT (GWP) & $0.29 \%$ & $0.60 \%$ & $0.86 \%$ & $0.49 \%$ \\
\hline CONSUMPTION & $-0.12 \%$ & $0.06 \%$ & $0.67 \%$ & $0.11 \%$ \\
\hline EDUCATION & $6.67 \%$ & $9.98 \%$ & $5.43 \%$ & $7.42 \%$ \\
\hline GENERIC R\&D & $0.39 \%$ & $0.53 \%$ & $0.79 \%$ & $0.46 \%$ \\
\hline ENERGY R\&D & $0.20 \%$ & $0.15 \%$ & $0.60 \%$ & $0.23 \%$ \\
\hline
\end{tabular}

Combining climate and education policy together suggests that the crowding-out effect of climate policy on education can be corrected at low welfare costs. Net present value results point at a

\footnotetext{
${ }^{9}$ Countries or population are classified on-track in achieving universal primary education if continuing on linear trends between 1990 and 2002 will result in a completion rate above 95\% by 2015. Off-track means that the completion rate is projected to be below 50\% in 2015 (seriously off track) or below 95\% (moderately off track).

${ }^{10}$ The implicit assumption is that average spending and the percentage of population off-track remain constant between 2000 and 2015.

${ }^{11}$ After 2015 SSA and SASIA continue spending at least the average amount required to have all population on-track.
} 
consumption and output gain, but these aggregate figures hide a trade-off between short-term and long-term consumption, which is analysed in Figure 3. In the short-term, education policy absorbs additional resources, reducing consumption possibilities. Short-term, additional education expenditure pays off in the long-term, when it increases overall economic growth, and ultimately consumption.

Figure 3. Consumption path in the two policy scenarios. Percentage changes w.r.t. BaU

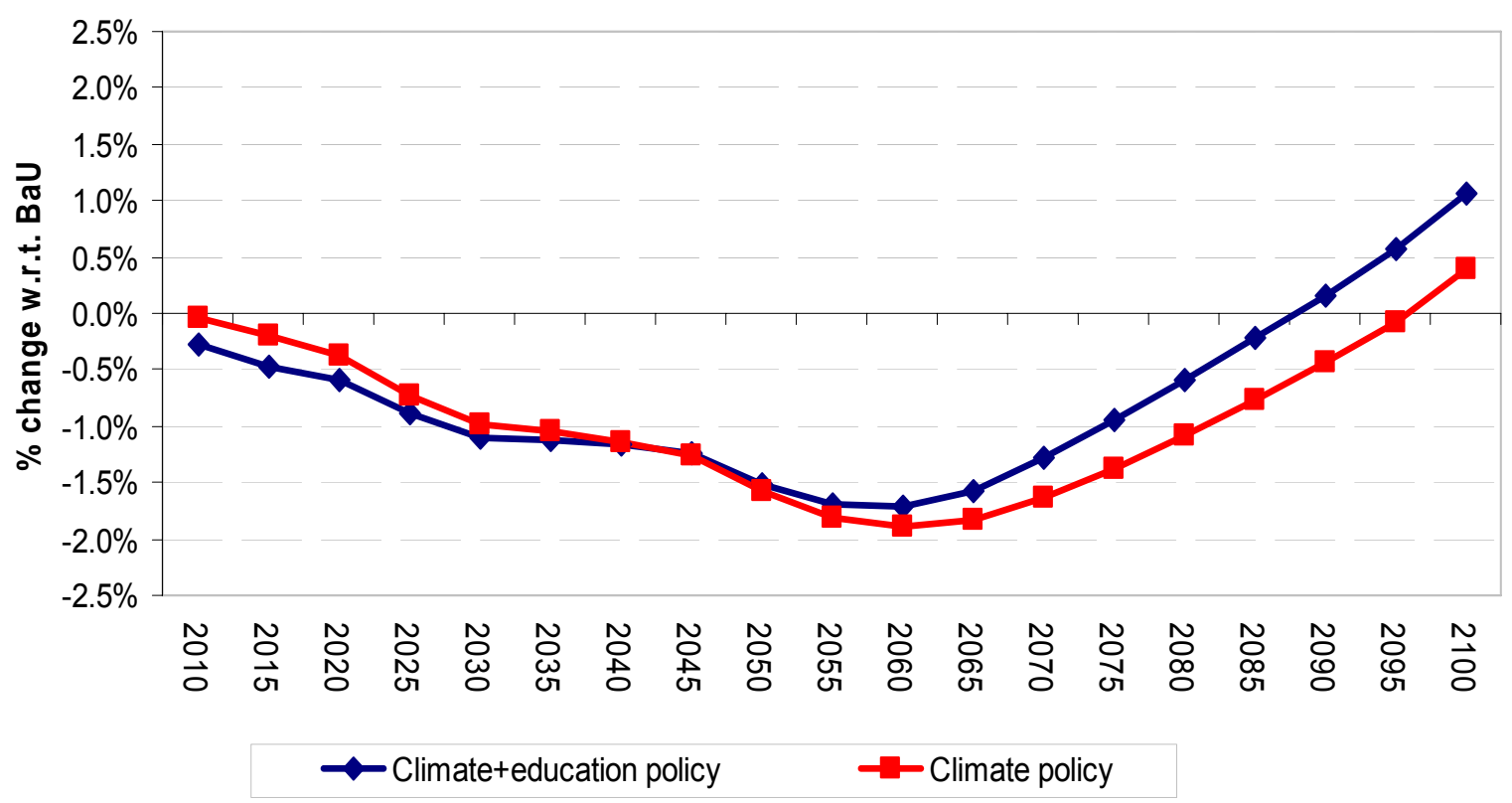

One limitation of the modelling approach proposed in this paper is the lack of interactions between knowledge and human capital. Enhanced human capital can be expected to ease knowledge formation. This is a very fruitful area for future research especially on the empirical side. To date, there are no studies that quantify the relationship between knowledge and human capital that can guide us in choice of the model specification. The next section provides a first exercise that illustrates what are the implications of omitting this interaction. This exercise should be considered a preliminary investigation of this issue, and a motivation for additional empirical work . 


\section{Knowledge Stimulating Education: a preliminary analysis}

In this section, we assume that the stock of human capital is an essential input for the formation of knowledge ${ }^{12}$. It can be reasonably assumed that investments in R\&D can be productive only if there are educated people that can work as researchers. Equation (12) describes the production of new knowledge, which depends not only on R\&D investments, but also on the stock of education expenditure:

$Z_{R D}(n, t)=\alpha_{R \& D} I_{R \& D}^{\beta_{R \& D}} R \& D_{S}^{\varphi_{R \& D}} E D U_{S}^{\varphi_{R \& D} / \gamma}$

where

$\beta_{R \& D}+\varphi_{R \& D}+\varphi_{R \& D} / \gamma<1$

With this specification, expenditure in education have an additional effect. It has an indirect impact on energy and capital productivity. To our knowledge ${ }^{13}$, there is no empirical evidence on the effect of education on knowledge formation. Therefore, the contribution of education has been chosen in relation to the one of $R \& D$. We have chosen an elasticity equal to one tenth the effect of R\&D (i.e. in equation $12 \gamma=10){ }^{14}$

Table 7 shows that when education contributes to knowledge formation, output and consumption losses are reduced. In fact, the crowding-out effect induced by climate policy is lower and therefore overall education investments are larger (Figure 4). As already explained in Section 3.2, education expenditure increases output and also mid- and long-term consumption.

Table 7. Effects of education on knowledge formation: sensitivity analysis

\begin{tabular}{|c|c|c|}
\hline & No effect & $\gamma=\mathbf{1 0}$ \\
\hline GWP (NPV 3\% discounting) & $-1.36 \%$ & $-0.70 \%$ \\
\hline Consumption (NPV 3\% discounting) & $\mathbf{- 0 . 9 4 \%}$ & $\mathbf{- 0 . 5 6 \%}$ \\
\hline
\end{tabular}

\footnotetext{
12 Most previous models assumed that labour (Jones, 1995; Aghion and Howitt, 1992) rather then educated people or human capital is used in the production of R\&D. Here the approach of Romer(1990) and of Ikazaki (2006) is followed.

13 To date, only empirical studies considers the joint effect of human capital and innovation on total factor productivity growth (Engelbrecht, 1997), which is however different from the relationship between human capital and innovation formation. That paper founds that the productivity effect of human capital is larger than the effect of R\&D.

${ }^{14}$ It is reasonable to expect the education effect on knowledge to be lower than the effect of both R\&D investments and capital stock. The size of this parameter is also constrained by the value of the other parameters and the restriction that the sum cannot exceed 1.
} 
When education helps to build up knowledge, climate policy induces a lower reduction in education investments because education has also an indirect effect on energy productivity. By augmenting the efficiency in knowledge production, education ultimately has an energy-saving effect. However, the direct, energy-using effect on labour productivity, prevails for this specific parameterization.

Figure 4. Human capital (education expenditure)

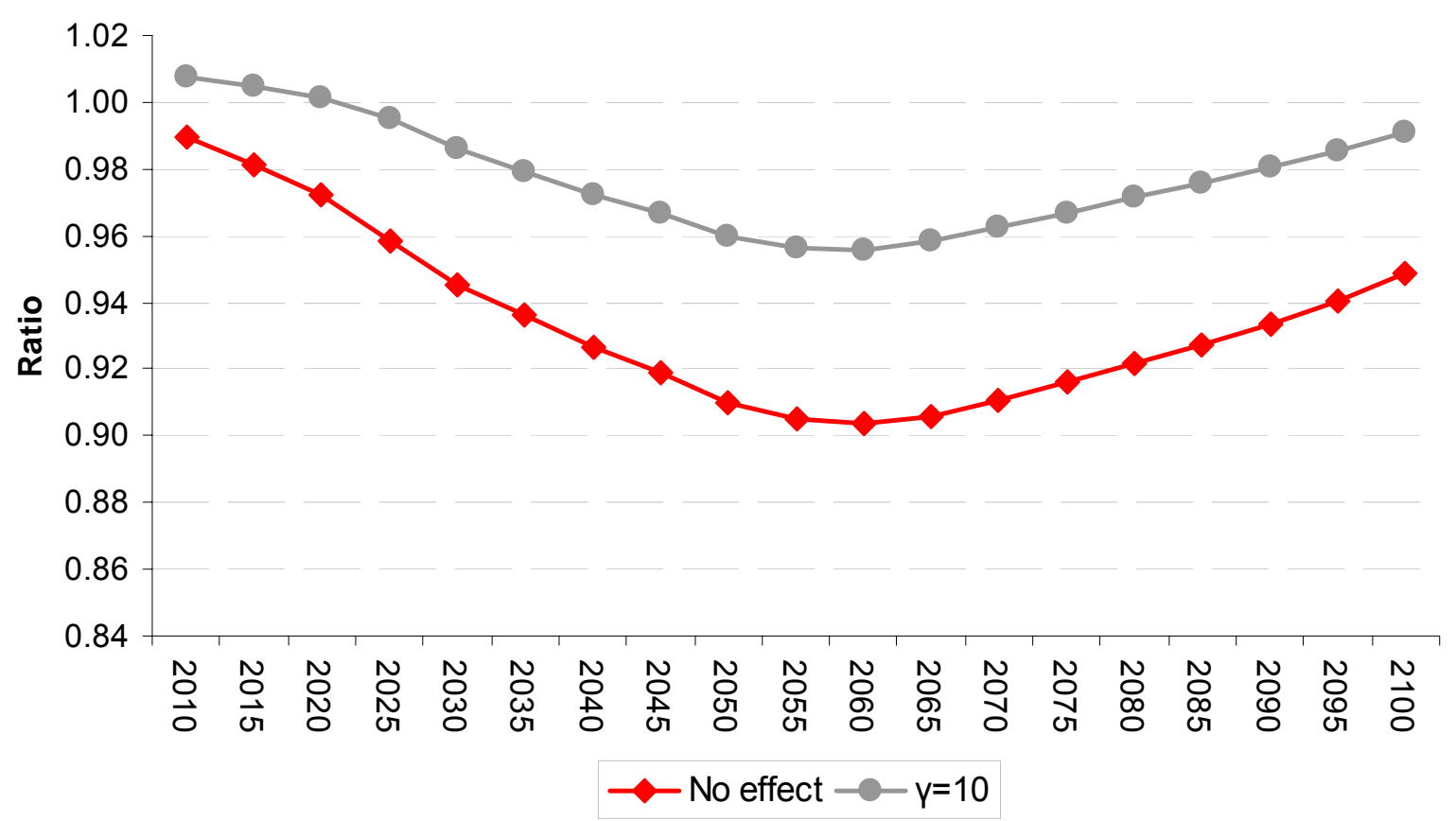

The figure plots the ratio of education investments in the stabilisation scenario over the baseline scenario

\section{Conclusions}

Most climate-economy literature has assessed climate policies in a first-best world, in isolation from other policy targets. However, there is an increasing awareness that the attainment of climate targets is conditional on solid economic development, good institutions and capacity.

This paper contributes to this debate by analysing the linkages between human capital and climate policy. An integrated assessment model is equipped with an empirical estimated representation of knowledge and human capital accumulation. The model features several forms of endogenous technical change, both in the energy sector and at the macroeconomic level. Knowledge, driven by a generic form of R\&D, increases the productivity of capital and energy. Human capital drives labour productivity growth. Dedicated innovation specifically addresses energy efficiency and the competitiveness of low carbon technologies. Using this framework, we have analysed how climate policy affect innovation in the energy sector, generic innovation and human capital formation. 
Results indicate that climate policy stimulates a dedicated form of energy-knowledge without reducing generic $R \& D$ investments because the effect of generic $R \& D$ on energy productivity outweighs the pollution using capital one. That is, complementarity between different types of knowledge is reported.

However, advancements in labour productivity have a negative impact on the environment because labour is a complement to energy. Education investments, on which human capital is built, decrease by at most $10 \%$ because of the capital-skill complementarity. However, inspection of a policy mix shows that education and climate goals can be coupled incurring in small additional economic penalties.

Finally, we have provided a first exploratory investigation of how the interdependence between $R \& D$ and education can affect modelling results. The negative effect of climate policy on human capital formation is lessened when the contribution of education to the formation of innovation is sufficiently large. That exercise is to be considered as a preliminary analysis meant to suggest the importance of additional empirical work in this area.

A further channel of interactions that could be considered in future works is the interdependence between domestic R\&D, education, and foreign knowledge. The inclusion of education investments as an endogenous variable in the model offers the possibility to enrich the specification of absorptive capacity to account for the role of both innovation and human capital. 


\section{References}

Acemoglu, D., P. Aghion, L. Bursztyn and D. Hemous (2009). "The Environment and Directed Technical Change," NBER Working Paper No. 15451, Oct 2009

Acemoglu, D. (2003). “Labor- and Capital-Augmenting Technical Change,” Journal of European Economic Association 1, 1-37

Blankenau W. and N. Simpson (2004). "Public education expenditure and growth,” Journal of Development Economics 73, (2), 583-605

Bosetti, V., C. Carraro, M. Galeotti, E. Massetti and M. Tavoni (2006). “WITCH: A World Induced Technical Change Hybrid Model,” The Energy Journal, Special Issue Hybrid Modelling of Energy Environment Policies: Reconciling Bottom-up and Top-down, 13-38

Bosetti, V. E. Massetti, M. Tavoni, (2007). “The WITCH Model. Structure, Baseline, Solutions,” Fondazione ENI Enrico Mattei, Nota di Lavoro 10-2007, Milan

Bosetti V., E. De Cian, A. Sgobbi and M. Tavoni (2009). “The 2008 WITCH Model: New Model Features and Baseline,” FEEM Working Paper 85-2009, Milan

Bosetti, V., C. Carraro and M.Tavoni (2009). “Climate Policy After 2012. Technology, Timing, Participation,” CESifo Economic Studies 55(2), 235-254

Bovenberg, A.L. and Smulders, S., (1995). "Environmental quality and pollution augmentation technological change in a two sector endogenous growth model," Journal of Public Economics 57, 369-391

Brock, William A. \& Taylor, M. Scott, 2005. "Economic Growth and the Environment: A Review of Theory and Empirics," in: Philippe Aghion \& Steven Durlauf (ed.), Handbook of Economic Growth, edition 1, volume 1, chapter 28, pages 1749-1821 Elsevier 
Carraro, C. And De Cian, E. (2009). "Factor-augmenting technical change: an empirical assessment,” DSE Working Paper, No. 29/09, Department of Economics, University of Venice

Carraro, C., E. Massetti and L. Nicita (2009). "How Does Climate Policy Affect Technical Change? An Analysis of the Direction and Pace of Technical Progress in a Climate-Economy Model” Fondazione ENI Enrico Mattei, Nota di Lavoro 08-2009, Milan

De La Gradville, O. (2007). "The 1956 contribution to economic growth theory by Robert Solow: a major landmark and some of its undiscovered riches," Oxford Review of Economic Policy 23 (1), $15-24$

Engelbrecht (1997). "International R\&D spillovers, human capital and productivity in OECD economies: An empirical investigation,” European Economic Review 41, 1479-1488

Gerlagh, R. (2008). “A climate-change policy induced shift from innovations in carbon-energy production to carbon-energy saving,” Energy Economics 30, 425-448

Glomm G. and B. Ravikumar (1992). "Public versus private investment in human capital: endogenous growth and income inequality,” Journal of Political Economy 100, 818-834

Goulder, L.H. and S. Schneider (1999). "Induced Technological Change and the Attractiveness of CO2 Abatement Policies,” Resource and Energy Economics 21, 211-253

Gradus, R. and Smulders, S. (1993). “The trade-off between environmental care and long-term growth-pollution in three prototype growth models,” Journal of Economics 58 (1), 25-51

Grimaud, A. and Tournemaine, F. (2007). "Why can environmental policy tax promote growth through the channel of education?,” Ecological Economics 62 (1), 27-36

Hettich, F. (1998). “Growth effects of a revenue-neutral environmental tax reform,” Journal of Economics 67 (3), 287-316.

Ikazaki, D. (2006). "R\&D, human capital and environmental externality in an endogenous growth model,” International Journal of Global Environmental Issues 6 (1), 29-46 
IPCC, (2007). Climate Change 2007: Mitigation. Contribution of Working Group III to the Fourth Assessment Report of the Intergovernmental Panel on Climate Change [B. Metz, O.R. Davidson, P.R. Bosch, R. Dave, L.A. Meyer (eds)], Cambridge University Press, Cambridge, United Kingdom and New York, NY, USA., XXX pp.

Jaffe, A.B. and Palmer, K, (1997). "Environmental regulation and innovation: a panel data study,” Review of Economics and Statistics 79, 610-619

Jones, C.I (1995). “R\&D - Based Models of Economic Growth,” Journal of Political Economy 103 (4), 759-784

Jorgenson D. and B. Fraumeni, (1992). "Investment in education and U.S. economic growth," Scandinavian Journal of Economics 94, S51-S70

Lucas R. E. (1988). “On the mechanics of economic development," Journal of Monetary Economics 22, 3-42

Lopez, R. (1994). “The environment as a factor of production: the effects of economic growth and trade liberalization,” Journal of Environmental Economics and Management 27, 163-184

Luderer, G., V. Bosetti, J. Steckel, H. Waisman, N. Bauer, E. De Cian, M. Leimbach, O. Sassi, M. Tavoni (2009): The Economics of Decarbonization - Results from the RECIPE model intercomparison. RECIPE Working paper, available online at http://www.pik-potsdam.de/recipe

Pautrel, X. (2008). "Environmental policy, education and growth: A reappraisal when lifetime is finite,” Fondazione ENI Enrico Mattei, Nota di Lavoro 57-2008, Milan

Pessoa, S. de Abreu, S.M Pessoa and R. Rob, (2005). "Elasticity of Substitution Between Capital and labour and its Applications to growth and Development,” PIER Working Paper 05-012, University of Pennsylvania

Popp, D. (2002). “Induced innovation and energy prices,” American Economic Review 1, 160-180 
Romer, Paul M. (1990). “Endogenous technological change,” Journal of Political Economy 98, 71-102

Smulders, S. and M. de Nooij, (2003). “The impact of energy conservation on technology and economic growth,” Resource and Energy Economics 25, 59-59

van der Werf, E. (2008). Production functions for climate policy modelling: an empirical analysis, Energy Economics, 30 (6), 2964-2979.

Yohe, G. (2001). "Mitigative capacity: the mirror image of adaptive capacity on the emissions side,” Climatic Change 49, 247-262 